\title{
ELEMENTOS PARA UNA RENOVACIÓN DE LA ENSEÑANZA DEL DERECHO FINANCIERO Y TRIBUTARIO: EL DISCERNIMIENTO DE LO JUSTO COMO METODOLOGÍA
}

\author{
Autor: Zulema Calderón Corredor. ${ }^{1}$ \\ Doctora de Derecho Financiero y Tributario. \\ Universidad Francisco de Vitoria.
}

\section{Resumen}

En este trabajo se proponen tres elementos para reflexionar y proyectar en la docencia del Derecho Financiero y Tributario, teniendo en cuenta los objetivos propuestos en las Guías Docentes y el marco de renovación al que invita el proceso de Bolonia:

El elemento teleológico o fin de la actividad financiera del Estado y el papel que juega el bien común en la justificación del deber de contribuir, como criterio de reparto y como concepto clave de unidad e interpretación de esta rama jurídica.

${ }^{1}$ z.calderon.prof@ufv.es 


\title{
Zulema Calderón Corredor
}

El elemento antropológico, por su relevancia como criterio normativo, elemento material de concreción de la justicia distributiva y fundamento y graduación del principio de subsidiariedad.

El elemento metodológico, que por coherencia con los anteriores debe aportar al alumno vías de conocimiento complementarias de una realidad tan compleja y multidisciplinar como la financiera y tributaria.

Palabras clave: Guía Docente, renovación docente, fines del sistema tributario, bien común, antropología y Derecho Tributario, metodología multidisciplinar, justicia distributiva.

Key elements to inspire the Teaching of Finance and Tax Law: Discerning what is fair as a methodology.

\begin{abstract}
In this paper we aim to suggest tree key elements to inspire the teaching of $\mathrm{Pu}$ blic Finance and Tax Law: the role of the common good as teleological criteria, the anthropological point of view in legal interpretation and the convenience of approaching the teaching method to the multidisciplinary nature of public finances and taxes.
\end{abstract}

Key words: Teaching Guide, tax system's role, common good, anthropology in Tax Law, multidisciplinary teaching methodology, distributive justice.

\section{LA DOCENCIA DEL DERECHO FINANCIERO Y TRIBUTARIO EN EL CONTEXTO DE BOLONIA.}

Una reflexión sobre la enseñanza del Derecho Financiero y Tributario en España debe por fuerza enmarcarse en el contexto actual de implantación del Espacio Europeo de Educación Superior, en su realidad, sus efectos y en los retos que plantea.

La apuesta por este proceso de armonización es la consecuencia natural de concebir las dimensiones intelectuales, culturales, sociales, científicas y tecnológicas como elementos esenciales de la Unión Europea. Con ello, la construcción de este Espacio Europeo de Enseñanza Superior se convierte en instrumento 
clave en la promoción de la movilidad de los ciudadanos, su ocupabilidad, y el desarrollo global del continente. Este objetivo se ha querido instrumentar otorgando a la educación superior en Europa unas señas de identidad que hicieran posible la comparabilidad, la compatibilidad, la movilidad y la unidad de medida entre instituciones educativas y Estados, sin olvidar la competitividad. El proceso de homogeneización que hiciera posible este objetivo y otorgara transparencia al sistema ha centrado la atención en los resultados del aprendizaje y en su evaluación más que en la enseñanza de conocimientos en sí misma. Se trata además de un proceso que pretende ser respetuoso con la diversidad de culturas, lenguas, sistemas nacionales de enseñanza y con la autonomía universitaria, otorgando protagonismo al desarrollo armónico de habilidades, competencias y destrezas ${ }^{2}$ en el aprendizaje del estudiante y desviando su atención de los contenidos.

Con la excusa de este proceso de adaptación se han multiplicado las aportaciones doctrinales ${ }^{3}$ relacionadas con la docencia del Derecho Financiero y Tributario, más allá de la ausencia de novedad de muchos de sus objetivos en las técnicas docentes que ya se venían aplicando en la educación superior. La gran mayoría de las aportaciones se concreta en propuestas de metodologías de enseñanza que combinan dos variables: la figura de un profesor que pasa de ser transmisor de sus conocimientos a ser un orientador y dinamizador del proceso de aprendizaje de los estudiantes y el uso de las nuevas tecnologías de la comunicación ${ }^{4}$.

Dentro de este marco se encuentran propuestas que inciden en cómo dar protagonismo al alumno además de control sobre su proceso de formación ${ }^{5}$ o en la resolución de casos prácticos de carácter interdisciplinar que permitan integrar distintas ramas jurídicas ${ }^{6}$. También se propone la adquisición de capacidades y

${ }^{2}$ Real Decreto 1125/2003, de 5 de septiembre, por el que se establece el sistema europeo de créditos y el sistema de calificaciones en las titulaciones universitarias de carácter oficial y validez en todo el territorio nacional. Una explicación de los distintos tipos de competencias transversales y específicas del Grado de Derecho puede encontrarse en Casana Merino, F., "Nuevas técnicas docentes en Derecho Financiero y Tributario", en Piña Garrido, L. (Coord.), VI Jornada metodológica de Derecho Financiero y Tributario "Jaime García Añoveros", La calidad jurídica de la producción normativa en España, . Doc 30/2009, pp. 153-158. Instituto de Estudios Fiscales. Madrid. 2009.

${ }^{3}$ Por citar solo algunas más recientes en el área destacan las comunicaciones y ponencias sobre la cuestión contenidas en dos trabajos recientes: Piña Garrido, L. (Coord.), VI Jornada metodológica op. cit., pp. 19-246 y en García-Herrera, C. (Coord.), VII Jornada metodológica de Derecho Financiero y Tributario "Jaime García Añoveros", Interpretación del Derecho Financiero y Tributario, La asignatura de derecho Financiero y Tributario en los nuevos planes de estudios, Doc 12/2011, Instituto de Estudios Fiscales, Madrid, 2011.

${ }^{4}$ Lopaz Pérez, A., "El aprendizaje del Derecho Financiero y Tributario en el escenario del Espacio Europeo de Educación Superior: Metodologías tradicionales versus metodologías activas", VI Jornada metodológica ... op. cit., pp. 213-216.

${ }^{5}$ González González, A. I. y Herrero de la Escosura, P., “Aplicación de nuevas metodologías docentes en Derecho Financiero y Tributario", VI Jornada metodológica ... op. cit., pp. 19-34.

${ }^{6}$ Bertrán Giron, M. y Pérez Lara, J. M., "Presentación del proyecto de innovación docente: Enseñanza del Derecho mediante supuestos prácticos interdisciplinares e interdepartamentales", VI Jornada metodologica ... op. cit., pp. 45-54. 


\section{Zulema Calderón Corredor}

habilidades mediante talleres de jurisprudencia y aprendizaje basado en problemas $^{7}$ (resolución de casos reales/simulados), intervención en foros de debate y tutorías $^{8}$, en el aprendizaje cooperativo ${ }^{9}$ o en las fases necesarias para implantar un sistema de evaluación de competencias ${ }^{10}$.

La adaptación de los temarios a las restricciones de tiempo que impone el nuevo sistema de créditos ECTS, ha afectado también al contenido de las asignaturas en las que se concreta la docencia del Derecho Financiero y Tributario, tanto en titulaciones jurídicas como no jurídicas. La prevalencia del Derecho Tributario, ya sea por la vía de los hechos en la práctica docente, por la amplitud de la materia o por el mayor interés que suscita de cara al ejercicio profesional, es uno de los fenómenos más destacados. La selección de contenidos en el nuevo marco que ofrece el EEES favorece aquellos que ofrecen un interés especial al alumno, y en particular los relacionales o los que estén conectados con la práctica profesional ${ }^{11}$. En todo caso destaca el esfuerzo por alcanzar el equilibrio adecuado entre la formación teórica y la práctica.

Pues bien, creemos que existe el riesgo de descuidar las claves interpretativas que subyacen en los contenidos de la asignatura y que deben iluminar este proceso de renovación metodológica. Estas claves son los elementos que configuran la obligación de contribuir y el diseño de un sistema tributario justo, claves que históricamente se han visto afectadas por contextos epistemológicos y antropológicos extraños a su esencia. En este trabajo se proponen esos elementos como caminos para la renovación docente.

\section{CONCEPTO DE DERECHO Y FORMACIÓN INTEGRAL DEL JURISTA.}

En el Libro Blanco del Título de Grado en Derecho se afirma que el objetivo primordial de los Planes de Estudios de Derecho es el de procurar una formación inte-

7 Pedreira Menendez, J y Pascual González, M., "Una propuesta de praxis metodológica en el Derecho Financiero y Tributario", VI Jornada metodológica ... op. cit., pp. 227-236.

${ }^{8}$ Bonet Sánchez, M ${ }^{a}$ P. y Alguacil Marí, M ${ }^{a}$ P., "Combinación de estrategias y metodologías para un aprendizaje efectivo del Derecho Tributario", VI Jornada metodológica ... op. cit., pp. 65-74; Aguilar Rubio, M. et alt., "El aprendizaje del Derecho Financiero y Tributario en el marco del EEES: experiencias desde la Universidad de Almería (I), VI Jornada metodológica ... op. cit., pp. 95-106.

${ }^{9}$ Malvárez Pascual, L. A., "Trabajo cooperativo a través de las plataformas de teleformación para la creación de materiales compartidos en el área de Derecho Financiero", VI Jornada metodológica ... op. cit. .pp. 107-118; Alarcón García, G., "El aprendizaje cooperativo como metodología para la enseñanza de la materia Sistema fiscal español", VI Jornada metodológica ... op. cit., pp.119-130.

${ }_{10}$ Romero García, F., "Evaluación de competencias en la enseñanza universitaria en el marco del EEES”, VI Jornada metodológica ... op. cit., pp. 87-94.

${ }^{11}$ Giné Freixes, N., "Cómo mejorar la docencia universitaria: El punto de vista del estudiantado", Revista Complutense de Educación, Vol. 20 Núm. 1, 2009. pp. 117-134. 
gral a nuestros juristas ${ }^{12}$. No obstante, la respuesta a la pregunta ¿qué es ser jurista?, dependerá de la concepción que se tenga del Derecho. No es lo mismo entender el Derecho como un conjunto de normas que concebirlo como un arte o praxis de discernimiento de lo justo y de lo injusto. Según nos encontremos en una u otra perspectiva la forma de enseñar nuestra asignatura será diferente, porque la realidad que constituye nuestro objeto se trasladará a distintos aspectos de la actividad docente. Así, los conocimientos que transmitamos, el sistema de fuentes que consideremos, la forma de interpretar el derecho aplicable o el significado de las instituciones jurídicas, serán reflejo de una actitud formal-legalista o de una concepción orientada a la justicia.

Por esta misma razón, la respuesta a los retos que conlleva el camino iniciado en Bolonia y los replanteamientos que nos invita a realizar responderán al posicionamiento que el docente mantenga respecto de su idea del Derecho, aunque se trate de una cuestión inconsciente o implícita. Ninguna forma de enseñar Derecho o de aprenderlo es neutral respecto de esta realidad, pues tanto el objeto como el método de conocimiento (científico) destilan una concepción concreta de lo jurídico.

En nuestra opinión, el jurista se forma en un arte que se ordena a la justicia, consistiendo ese arte en un proceso de discernimiento de la solución justa que va más allá de la aplicación del derecho vigente al caso concreto. Esta, además, es la impresión que se desprende de la práctica jurídica cotidiana cuando se recurre por ejemplo al uso de principios impositivos generales para interpretar la ley o cuando se utilizan razonamientos no normativos o conceptos que sirven para llenar de significado categorías legales que el Derecho positivo no alcanza a definir: enriquecimiento injusto, buena fe, principio de solidaridad, autonomía financiera, principio de reciprocidad, principio de no discriminación, etc.

La introducción de un nuevo sistema de evaluación en la enseñanza superior, ha cambiado notablemente la naturaleza de las cuestiones que se evalúan en los estudiantes. Junto a los componentes tradicionales de esa evaluación, se han introducido competencias que van más allá del conocimiento de contenidos e incluso del desarrollo habilidades de resolución de cuestiones de la práctica profesional $^{13}$ (aptitudes). Las denominadas competencias transversales (generales) incluyen la formación de actitudes en el alumno, tales como el compromiso ético o la sensibilidad hacia temas de la realidad social, económica y medioambiental ${ }^{14}$. En particular, el "compromiso ético, ... mediante la consideración de la trascenden-

${ }_{12}$ En el epígrafe correspondiente a las competencias y perfiles profesionales de los licenciados en Derecho. ANECA. Libro Blanco del Título de Grado en Derecho, Lorenzo Merino, F. (Coord.), Vigo, junio de 2005.p. 91.

13 Estos corresponderían a las competencias específicas: competencias académicas, conocimientos disciplinares (hacer) y competencias profesionales (saber hacer). Cfr. ANECA. Libro Blanco del Título de Grado en Derecho. op. cit., p. 92.

${ }^{14}$ ANECA. Libro Blanco del Título de Grado en Derecho. op. cit., p. 103. 
cia política, económica, social y jurídica del deber de contribuir al sostenimiento de los gastos públicos"15 o la capacidad de "aprender a analizar críticamente la dimensión ética y política de las instituciones y de los problemas y las soluciones jurídicas" ${ }^{16}$. Son competencias que apelan a un tipo de formación, al cultivo de disposiciones y de "formas de mirar el mundo", que difícilmente puede valerse solo de los modelos que aporta la legislación. Las leyes además, pueden moldear conductas, obligar a hacer o a no hacer, pero no pueden trasformar las actitudes, el ser del alumno. El camino a seguir propuesto por Bolonia parece invitar a un descubrimiento previo de la realidad sobre la que se aplica lo jurídico, un conocimiento que ofrezca razones y que comprometa al alumno.

Esta realidad meta-jurídica o formación atemporal en los conocimientos fundamentales del Derecho ${ }^{17}$, en ocasiones, puede no hacerse explícita en la docencia del Derecho Financiero y Tributario. Se trata de un sustrato o un fundamento filosófico ${ }^{18}$ que se incorpora al lenguaje y a las formas de razonar sobre la realidad y las instituciones jurídicas, especialmente en la medida en que carecen de un referente empírico inmediato. Por otra parte, la prioritaria atención al Derecho positivo es una tendencia comprensible en los planes de estudio, y más en un área jurídica en la que rige el principio de reserva de ley ${ }^{19}$. No obstante, este fundamento filosófico constituye una concepción de la realidad y de la forma de conocerla sobre la que el Derecho se asienta y se proyecta, y que existe tanto en la visión normativista como en la orientada al discernimiento de lo justo. Podíamos entonces preguntarnos: ¿cuál es la concepción del Derecho que subyace a nuestra docencia? o ¿cuál es la filosofía jurídica que de forma implícita se encuentra en las guías docentes de las asignaturas en las que se enseña el Derecho Financiero y Tributario?.

Una de las actividades académicas más representativas de la existencia de este sustrato teórico es el análisis de los principios impositivos que inspiran nuestro

${ }^{15}$ Ramos Prieto, J., Guía Docente de la asignatura de Derecho Financiero. Experiencia piloto de aplicación del sistema europeo de créditos (ECTS), Universidades Andaluzas-Universidad Pablo Olavide. Sevilla. Estudios Conjuntos Derecho/ADE. Curso académico: 2011-2012. Competencias específicas actitudinales. p. 6.

${ }^{16}$ Arrieta Martínez de Pisón, J.; Delgado Pacheco, Abelardo; Gandarillas Martos, S.; et alt. Guía docente de la asignatura de Fundamentos de Derecho Financiero y Tributario ( $3^{\circ}$ Grado en Derecho). Universidad Autónoma de Madrid. Curso 2013-2014. p. 4.

${ }^{17}$ Competencias y su evaluación. Extracto de la Memoria de Verificación del Título de Grado en Derecho. Universidad Pontificia Comillas. Competencias específicas académicas. 2013. p. 7.

${ }_{18}$ Aunque puede encontrarse quien afirme que el impuesto es prácticamente el único campo en el que no se ha aventurado una modalidad elevada de pensamiento debe reconocerse que existe una filosofía fiscal que se remonta a la Antigüedad y que la Ciencia de la Hacienda también se ha ocupado de la justicia tributaria. Tipke, K. Moral tributaria del Estado y de los contribuyentes. Marcial Pons. Madrid. 2002. p. 23.

19 Art. 31.3 de la Constitución Española: "Sólo podrán establecerse prestaciones personales o patrimoniales de carácter público con arreglo a la ley.” y art. 14 de la Ley 58/2003, de 17 de diciembre, General Tributaria. 
sistema tributario y el estudio de la llamada doctrina principialista. Pues bien, coincidimos con la observación que realiza H. SIMONS según la cual ningún análisis de los principios de la imposición puede hacerse con rigor sin antes plantear explícitamente los presupuestos filosóficos en ellos subyacentes ${ }^{20}$. Por otra parte, existen en la actualidad importantes cuestiones puestas de manifiesto por la práctica fiscal o por la doctrina que reclaman una profundización en su fundamento o un replanteamiento en su interpretación. Así por ejemplo, el conflicto entre los principios de justicia y eficiencia ${ }^{21}$ impositiva en los sistemas fiscales modernos, las vicisitudes del principio de capacidad económica en su relación con los fines extrafiscales de los tributos ${ }^{22}$, la posible colisión entre el ordenamiento constitucional y el comunitario ${ }^{23}$ o el deber mismo de contribuir ${ }^{24}$, son cuestiones a las que un estudio de los fundamentos puede aportar mucha luz. También en el ámbito docente. Por otro lado, el proceso de renovación al que nos invita la Declaración de Bolonia, constituye un nuevo motivo para reflexionar en la filosofía fiscal sobre la que se asienta el arte de discernir lo justo de lo injusto.

20 Simons, H., The Personal Income Taxation. University Chicago Press. reimpresión de 1948, citado por Pérez de Ayala, J. L. "Las cargas públicas: principios para su distribución”, Hacienda Pública Española, $\mathrm{n}^{\circ} 59,1979$. p. 88.

${ }^{21}$ A pesar de la falta de reconocimiento expreso del principio de eficiencia en el texto constitucional, la interpretación doctrinal de los principios tributarios sí recogidos entendió que la eficiencia económica en la asignación de los recursos así como el respeto a otros derechos constitucionalmente protegidos podían entrar en colisión con los principios anteriores. La globalización económica y el fenómeno de la deslocalización de inversiones han puesto de manifiesto tensiones importantes entre ambos principios. La literatura que trata estas cuestiones es abundantísima, siendo una muestra de la que refleja esta realidad la siguiente: Martín Delgado, J M., "Los principios de capacidad económica e igualdad en la Constitución Española de 1978", Hacienda Pública Española, n 60, Madrid. 1979. p. 83; Cortés Domínguez, M., "El principio de capacidad contributiva en el marco de la técnica jurídica", Revista de Derecho Financiero y Hacienda Pública, no 61, 1965. pp. 986-987. Valle, V., "Una nota sobre los principios impositivos en perspectiva histórica", Papeles de Economía Española, n 87, 2001. p. 53; Caamaño Anido, M.A. y Calderón Carrero, J. M., "Globalización económica y poder tributario: ¿hacia un nuevo Derecho Tributario?", Revista española de Derecho Financiero, n 114, 2002, p. 247.

${ }^{22}$ La evolución del principio de capacidad económica como criterio para expresar la igualdad en el ámbito tributario ha sido objeto de muchas aportaciones doctrinales. Por todas, señalamos tres: Albiñana, C., "Los tributos con fines no financieros". Economía española, cultura y sociedad. Homenaje a Juan Velarde. Tomo II, Eudema, Madrid, 1992; Palao Taboada, C., "Apogeo y crisis del principio de capacidad contributiva", Estudios jurídicos en homenaje a Federico de Castro, Tecnos. Madrid, 1976. pp. 377-426 y "Nueva visita el principio de capacidad contributiva", Revista Española de Derecho Financiero, no 124 , Cívitas, 2005. pp. 767-783.

${ }^{23}$ Escribano López, F., "Algunas propuestas metodológicas para la (re)construcción de un Derecho Financiero del siglo XXI", I Jornada Metodológica "Jaime García Añoveros" sobre la metodología académica y la enseñanza del Derecho Financiero y Tributario. Documento n ${ }^{\circ}$ 11/02, Instituto de Estudios Fiscales, 2002. p. 33.

${ }^{24}$ La objeción de conciencia fiscal es una cuestión sobre la que se ha pensado mucho, y más cuando el contribuyente tiene serias dudas de la legitimidad en el uso de los recursos públicos. Como muestra destaca este interesante análisis histórico-filosófico de la cuestión: Perez de Ayala, J. L., "El fundamento deontológico del impuesto, de la Ley fiscal y de la obligación tributaria", en VV.AA.: I Jornada Metodológica ... op. cit., pp.285-310. 
Con este objetivo se apuntan a continuación algunos elementos que pueden servir primero para la reflexión y después para ser proyectados en aspectos muy concretos de la docencia y de la elaboración de las guías docentes.

\section{ELEMENTO TELEOLÓGICO EN LA ACTIVIDAD FINANCIERA Y TRIBUTARIA: EL BIEN COMÚN.}

El Derecho Financiero y Tributario, como ordenación jurídica de la actividad financiera de las Administraciones públicas, tiene por fuerza que plantearse cuál es su fin, pues toda actividad humana se dirige a un objetivo. No obstante, esta pregunta no siempre se hace explícita en los manuales de la asignatura o se responde aludiendo a la satisfacción de necesidades colectivas o públicas, fines públi$\cos ^{25} \mathrm{O}$ fines de carácter político ${ }^{26}$. Al atribuir a esta actividad una naturaleza política (económica y jurídica) y asumir que las directrices las asume un sujeto público ${ }^{27}$, la idea de fin aparece ligada a una voluntad, la del Estado, no a una realidad, la de la sociedad. No obstante, se trata de una literatura que no renuncia a la existencia de un ideal de justicia como legitimación de los ingresos y gastos públicos, ideal abstracto, que representa el Derecho ${ }^{28}$ aunque luego adopte el marco constitucional positivo como único límite al criterio político.

Ese anhelo del ideal de justicia se manifiesta especialmente por el lado de la asignación equitativa de los gastos públicos (art. 31.2 CE) y en el reconocimiento de que es al jurista al que corresponde emitir juicios de valor al respecto ${ }^{29}$. En este sentido, se afirma: "En este punto hay una circunstancia que dificulta sensiblemente la penetración de principios materiales de justicia en el ámbito del ordenamiento de los gastos públicos: el carácter esencialmente político de la decisión presupuestaria. Naturaleza política de la decisión presupuestaria y límites de carácter estrictamente jurídicos son conceptos difícilmente armonizables" ${ }^{\text {30 }}$.

Un último motivo para proponer a nuestros alumnos una reflexión de la asignatura desde el punto de vista teleológico, es la afirmación contenida en unas

${ }^{25}$ Carrera Raya, Fco. J., Manual de Derecho Financiero, Vol. I, Derecho Financiero y Teoría de los ingresos públicos, Ed. Tecnos, Madrid, 1993. p. 26.

${ }^{26}$ En algunos manuales se menciona solo que los ingresos públicos son para ser destinados a determinados fines, como en el caso de Collado Yurita, M.A. y Luchena Mozo, Gracia M., Derecho Tributario. Parte general, Atelier. 2a edición, Barcelona, 2007. p. 27. En otros se plantea expresamente su carácter político: Queralt, J. M.; Lozano Serrano, C.; Tejerizo López, J. M. Y Casado Ollero, G., Curso de Derecho Financiero y Tributario, Tecnos, $20^{a}$ edición, Madrid, 2009. p. 31.

27 Carrera Raya, Fco. J., Manual de Derecho Financiero, ... op. cit., p. 27.

28 Ibídem, p. 87.

${ }^{29}$ Queralt, J. M. et. alt. Curso de Derecho Financiero y Tributario. op. cit., p. 35.

30 Ibídem, p. 37. 
Notas de introducción al Derecho Financiero: "Saber es discernir (apariencia de realidad, lo que no es de lo que es), es definir o poner límites y sobre todo saber es conocer el por qué.... Este saber puede equipararse al concepto de ciencia"31.

\section{a.- Como justificación del deber de contribuir}

Uno de los objetivos primeros que busca la asignatura de Derecho Financiero y Tributario puede expresarse así: "Comprender las razones que justifican la existencia de la actividad financiera pública y entender la idea de realización de la justicia a través del sistema financiero y tributario público, profundizando en la conexión entre los ingresos y los gastos públicos"32.

Se trata de transmitir a los alumnos el fundamento del deber de contribuir que recoge nuestra Constitución (art. 31.1), justificación que se encuentra en la propia realidad humana en la que surge el Derecho ${ }^{33}$. Esa realidad es la de un ser social que convive con otros de forma espontánea y que establece relaciones de las que derivan una serie de bienes ${ }^{34}$. Junto a los bienes individuales que esa sociedad fomenta y protege, y los derivados de las transacciones entre sus miembros (relaciones de equivalencia o de reciprocidad), existe un bien del que todos participan según sus circunstancias y que complementa los bienes anteriores: el bien común. Se trata de un bien que se genera a través de la convivencia y la relación humanas, que contribuyen a crear los individuos, las familias, las instituciones sociales y los organismos públicos. Este bien común genera unas necesidades de financiación y gestión, para mantenerlo y para comunicarlo a la sociedad, convirtiéndose por ello en fundamento del deber de pagar tributos. En este deber de contribuir se dice que la justicia está ordenada al bien común, situándose el discernimiento de lo justo en el contenido de la idea de bien común y en la parte del mismo que

31 Abad Díaz M. et alt., Notas de introducción al Derecho Financiero, Tecnos, Madrid, 1992. Comienza sus notas explicando cual es la relación entre fenómeno y ciencia. Distingue conocimiento vulgar (apariencia) del causal y dentro de este a su vez el científico (causas próximas) y el filosófico (causas últimas del objeto). Seguidamente ofrece el conocimiento de ciencia transcrito más arriba. pp. 13-14.

32 Arrieta Martínez de Pisón, J. et. alt., Guía docente de la asignatura de Fundamentos de Derecho Financiero y Tributario. op. cit., p. 3.

33 En algún manual de la asignatura al definir el fenómeno financiero se menciona la idea de proyecto de vida en común dirigido a unos fines y con ello la necesidad de contar con los recursos necesarios. El enfoque es desde la idea de necesidades comunes. Cfr. Abad Díaz M. et alt., Notas de introducción ... op. cit., pp. 13 y ss.

${ }^{34}$ Las primeras elaboraciones doctrinales sobre el fundamento del deber de pagar tributos tuvieron como marco las aportaciones de Aristóteles en su Ética a Nicómaco, Alianza Editorial, 2004. Estas aportaciones se asentaban en una concepción del hombre como ser naturalmente social y político y tuvieron como fruto el perfilamiento de lo que se conoce como Justicia General (o legal, la que deriva del bien común) y Justicia Particular (lo que se le debe a un tercero en sus dos formas: conmutativa y distributiva). Villey, M., Filosofía del Derecho, Scire Universitaria, Barcelona, 2003. pp. 48-53. Traducción de Evaristo Palomar Maldonado. 


\section{Zulema Calderón Corredor}

debe gestionarse públicamente y financiarse con tributos. Este discernimiento permitirá establecer mejor los contornos de cuestiones centrales en nuestra disciplina como pueden ser el derecho de propiedad, la libertad de empresa o la posible confiscatoriedad de un tributo. En torno a la realidad del bien común hay toda una Teoría del Estado y sus fines, como la hay sobre el hombre y su vida en sociedad.

La fundamentación del deber tributario, un deber de justicia que se encuentra en íntima relación con el contenido del bien común y con el papel del Estado y de la sociedad en su realización, se ha visto históricamente afectado por dos fenómenos. Esos dos fenómenos han sido la evolución que ha experimentado la actitud humana respecto de la posibilidad de conocer la realidad y el nacimiento del Estado moderno en torno a la idea del contrato social.

Por un lado, la afirmación kantiana de que el único conocimiento posible es el de los fenómenos y de que no se dispone de más intuición que la sensible, fue el resultado del proceso histórico de búsqueda de certezas inaugurado por la duda cartesiana y preparado por la negación nominalista de las categorías universales ${ }^{35}$. De ahí a la proclamación de la "nueva ciencia" cuya pureza fuera preservada por la observación, el experimento, la neutralidad ética, la preferencia de la matemática a la lógica... había solo un paso. Ese paso lo dio Comte, al confirmar desde el positivismo científico ${ }^{36}$ la edad positiva del hombre que en un proceso de maduración había dejado atrás las consideraciones teológicas y metafísicas. Pero se dejó por el camino el mundo de las causas y de los fines, el de las esencias, y con ello una comprensión más completa del ser y del mundo, también la comprensión de conceptos tan relevantes como el bien común.

Es decir, el interés y centralidad de la idea de bien común en el proceso de discernimiento de lo justo, más abstracta, relativa a un concepto previo de fin y en la que la comunidad interviene como parte activa, resultan paulatinamente

${ }^{35}$ El inicio del progresivo abandono de la epistemología realista consolidada desde Aristóteles puede situarse hacia el S. XIV con el desarrollo de una filosofía que reacciona frente al realismo tomista y escotista. Se produce una tendencia en la teoría de conocimiento durante la modernidad que ha sido definida como un modelo epistemológico que se esfuerza por constreñir la realidad en una serie de objetividades unívocas y homogéneas a las que se puede acceder, sin temor a errar, por un método adecuado. Podría definirse también como el intento de proponer una lectura matemática de la realidad física y social, entendida de forma mecanicista y sujeta a representación, sin admitir profundidad en la misma ni misterio alguno. Sus máximos exponentes son Galileo, Descartes y Hobbes. Alusiones a este fenómeno pueden encontrarse en: Truyol y Serra, A., Historia de la Filosofía del Derecho y del Estado, Vol. 1. De los orígenes a la baja edad media, Alianza, Madrid, 1995, $12^{a}$ edición. pp. 409 y ss; Valverde, C., Génesis, estructura y crisis de la modernidad, BAC, Madrid, 1996. pp. 10 y ss.

${ }^{36}$ En opinión de Dalmacio Negro el constructivismo nacido del cartesianismo y el hobbesianismo suscitan el positivismo. Augusto Comte lo transforma en una filosofía científica y libera los hombres de ciencia de las preocupaciones metafísicas. Negro, D., Lo que Europa debe al Cristianismo, Unión Editorial, Madrid, 2004. p. 47.; Vallet también se refiere a este fenómeno cuando describe el positivismo lógico: pretende convertir a la filosofía en una ciencia dedicada al análisis de los conceptos y de los métodos de las ciencias experimentales. Cfr. Vallet de Goytisolo, J.B., "Derecho y economía"; Iglesias Prada, J. L. (Coord).: Estudios jurídicos en homenaje al profesor Aurelio Menéndez, Vol IV, Cívitas. 1996. p. 5554. 
desplazados por una preocupación más concreta y mensurable, atendida por el Estado: la redistribución de la renta y el bienestar de la mayoría. La justicia material en el ámbito financiero y tributario dejará de buscarse en la realidad social y se centrará en el ámbito de la legalidad.

Por su parte, el nacimiento del Estado moderno tiene lugar sobre una teoría política, la del contrato social, basada en la idea de un hombre que no es ni social ni político ${ }^{37}$. Sólo puede llegar a serlo mediante un acuerdo o consenso artificial. Este modelo le otorga al Estado el protagonismo en la realización del bien común y se traduce históricamente en la utilización del Derecho como herramienta al servicio de distintos intereses. Esta filosofía se puede trasladar a las guías docentes cuando describen como una de las competencias específicas "la comprensión de la importancia del Derecho como sistema regulador de las relaciones sociales y económicas" 38 o cuando se afirma que "ante determinadas necesidades políticas o económicas surge la perentoriedad de establecer una nueva situación tributaria que modifique ciertas conductas o las diversas realidades que existen en cada país, para reconducirlas a aquella que desde los poderes públicos y los grupos de influencia social se considera en ese momento la adecuada" 39.

Coincidimos con Soler Roch ${ }^{40}$ cuando afirma que el componente ideológico es un factor que apenas se explicita y que transciende en las aportaciones dogmáticas y en la forma de entender las relaciones entre el Estado y los ciudadanos. En nuestra opinión, la identificación de ese componente y el análisis de sus

37 Dentro de los filósofos individualistas modernos se encuentran distintas variantes al análisis del "estado de naturaleza" de Hobbes y su propuesta de Contrato Social (los "derechos naturales de los individuos" con Locke, menos pesimista que Hobbes, o Wolf, entre otros, o el utilitarismo de J. Bentham (1748-1832)), siendo el origen de muchas de estas aportaciones nuevamente una concepción individualista de la naturaleza humana. Esta teoría parte de" la existencia de una situación pre-social en la que los individuos viven aislados sin ningún tipo de cooperación. Cada uno realiza su propia producción y se preocupa de defenderla. Estos individuos pre-sociales se dan cuenta, sin embargo, de que pueden mejorar su situación mediante la cooperación y, como resultado, se reúnen en asamblea para establecer los principios que han de regular su unión. (...) Los términos de este acuerdo libremente aceptado por todos los miembros de la sociedad constituyen el contrato social." Cfr. Zubiri, I., "Justicia distributiva: enfoques nuevos a un problema antiguo", Hacienda Pública Española, n 91, 1984. pp. 280-281. La teoría del pacto social ha sido contestada por muchos autores y desde distintos puntos de vista, especialmente el que tiene que ver con su desconocimiento de la sociabilidad natural del hombre. Hervada Xiberta, J., ¿Qué es el derecho? La moderna respuesta del realismo jurídico. Eunsa, Pamplona, 2008. $2^{\text {a }}$ edic. pp. 176-177.

38 Se trata de una competencia recogida por la ANECA en el Libro Blanco del Título de Grado en Derecho. op. cit., .p. 181. Su recepción en las guías docentes es muy amplia, citando a continuación solo algunas: Colao Marín, P. A.; Pastor del Pino, $\mathrm{M}^{\mathrm{a}}$ C., Guía docente de la asignatura de Derecho Financiero y Tributario ( $4^{\circ}$ Grado en ADE). Universidad Politécnica de Cartagena. Curso 2012-2013. p. 5.

${ }^{39}$ Almudí Cid, J.M. y Martínez Lago M.Á., "Presente y futuro de la enseñanza del Derecho Financiero y Tributario en la Universidad Complutense de Madrid: estudios de grado, posgrado y viabilidad de una "clínica jurídico-tributaria", Comunicación al IV Congreso Nacional de Innovación Docente en Ciencias Jurídicas. 2011. p. 5.

${ }^{40}$ Soler Roch, $\mathrm{M}^{\mathrm{a}} \mathrm{T}$., "Reflexiones sobre la evolución del concepto del Derecho Financiero", I Jornada Metodológica ... op. cit., p. 61. 
consecuencias es fundamental a la hora de situarse ante el Derecho como sistema regulador de conductas o como una praxis de búsqueda de la solución justa.

\section{b.- Como criterio para el reparto justo de las cargas públicas}

Una vez justificado el deber de contribuir, queda pendiente la indagación de cómo llevar a cabo un reparto justo, y de preguntarse conforme a qué criterios puede medirse la igualdad (justicia como igualdad) en el ámbito tributario. El tributo, como deuda en favor de la comunidad, puede incluirse entre las relaciones que desde el todo social se proyectan a cada individuo, luego su cuantificación y efectivo reparto quedarían vinculados al ámbito de la justicia distributiva ${ }^{41}$, no de forma exclusiva pero sí más relevante. Para determinar el criterio de medida en este reparto, el criterio que permite expresar la relación de igualdad en que consiste la justicia, habrá que considerar la distinta relación que guarda cada contribuyente con el fin de la distribución, esto es, el elemento teleológico ${ }^{42}$. En el caso de los tributos el fin es el sostenimiento de las cargas públicas derivadas del bien común. Tratándose de una cuestión de levantamiento financiero de cargas el criterio de reparto que parece más razonable es el de capacidad económica para afrontarlas. Criterio no muy diferente al que naturalmente rige en comunidades humanas más pequeñas e incluso en la familia.

La virtualidad y proyección histórica de la justicia distributiva como forma de justicia material en los tributos y su expresión mediante un gravamen proporcional a la capacidad económica, han contado con numerosas vicisitudes. La propia actitud epistemólogica que se gesta durante la modernidad y que se comentó más arriba, frustró muchos intentos de concretar una medida de esa capacidad económica a partir de signos relevantes y en contextos sociales cada vez más complejos. No es otra la razón del desengaño que expresa GIANNINI ${ }^{43}$ en su búsqueda de certezas, cuando afirma: "sería ciertamente deseable que un soberano criterio

${ }^{41}$ La justicia distributiva o asignadora es aquella forma de justicia que puede predicarse de la relación entre el todo social, poder político o Estado y los ciudadanos. En este caso el acreedor tributario no es considerad aisladamente, sino comparativamente, es decir, en relación con todos los demás. Consiste en una forma de expresión de la justicia en la que el reparto se traduce en pasar de lo común a lo particular. La diferencia frente a la justicia conmutativa está tanto en la cosa que le debida como en el modo en que tiene de serle debida. Radbruch, G., Introducción a la filosofía del Derecho, 1948. Traducción española. edit. Fondo de cultura económica. $1^{\text {a }}$ Ed. 1951. México. D.F. 1993. $5^{\text {a }}$ reimpresión. pp. 31 y ss. Aunque tanto Santo Tomás, como Aristóteles, refieren la justicia distributiva principalmente al reparto de bienes comunes entre los ciudadanos, también se ha entendido referida a las cargas comunes que la colectividad debe atribuir a cada uno de sus miembros.

${ }^{42}$ Hervada Xiberta, J., Lecciones propedéuticas de filosofía del derecho, $3^{\mathrm{a}} \mathrm{Ed}$, edit. Eunsa, Pamplona, 2000.p. 222. Hervada se refiere a distintos criterios de reparto en los que puede expresarse la justicia distributiva en forma de relación o de proporción: factores como la condición, la capacidad, la aportación a la sociedad, la función y la necesidad.

${ }^{43}$ Cit. por Palao Taboada, C., "Apogeo y ... op. cit, pp. 379-380. 
de justicia distributiva presidiese toda la imposición, pero esta es una exigencia ideal, cuya realización, como en cualquier otro campo de la vida social, está encomendada a la prudente apreciación del legislador".

Por su parte, la dogmática jurídica, en el proceso de construcción sistemática de un Derecho Financiero y Tributario con categorías jurídicas propias y acreedor de autonomía científica, sustituyó el concepto de tributo como relación de poder por el de tributo como relación jurídica. Para ello, trasladó los esquemas de relación de la teoría de obligaciones del Derecho Civil al Derecho Financiero (con sus especialidades), esquemas más cercanos a la relación de igualdad de la justicia conmutativa que a la relación de igualdad de la justicia distributiva. Esto, unido a la depuración de elementos "extrajurídicos" en la dogmática, la desatención de cualquier consideración histórica, política, filosófica o teleológica del tributo, dejó fuera cuestiones clave en torno a las que proyectar el sentido y alcance del principio de capacidad económica. La proliferación de los fines asignados al Estado por medio del Derecho Financiero y Tributario (poder político=poder financiero) incrementó las presiones que ya soportaba este principio. La doctrina entiende superada esta fase de pureza metodológica y de prejuicio dogmático pues "ha pasado a concebirse la relación obligatoria de naturaleza tributaria y las potestades públicas de la Administración como instrumentos al servicio de la realización de los principios materiales de justicia”"44. En nuestra opinión, la situación actual del principio de capacidad económica, reconducido al de igualdad e interpretado como mera exigencia de interdicción de la arbitrariedad ${ }^{45}$, no refleja esa superación.

\section{c.- Como fundamento de unidad y criterio de interpretación}

Una de las competencias específicas que deben adquirir los alumnos al aprender los Fundamentos de Derecho Financiero y Tributario es "demostrar la capacidad de pronunciarse con una argumentación jurídica convincente sobre una cuestión teórica de complejidad media relativa a las diversas materias del Derecho Financiero y Tributario" ${ }^{46}$. Se trata de una competencia que precisa construirse desde una visión unitaria de este ordenamiento y desde la comprensión de la misión integradora de las instituciones jurídicas. No obstante, el reconocimiento

${ }^{44}$ García Novoa, C., "Algunas reflexiones sobre cuestiones de concepto y método en Derecho Financiero y Tributario”, I Jornada Metodológica ... op. cit., p. 120.

${ }^{45}$ Herrera Molina, P. M., Capacidad económica y sistema fiscal. Análisis del ordenamiento español a la luz del Derecho alemán. Prólogo de K. Tipke, Marcial Pons, Madrid, 1998. pp. 23 y ss. El autor, tras reconocer esta situación, se propone en su trabajo "liberar" el principio de capacidad económica que como resultado de la misma se encuentra apresado en la construcción dogmática de la interdicción de la arbitrariedad. Para ello se propone demostrar que existe un derecho fundamental a contribuir a las cargas públicas con arreglo a la propia capacidad económica.

${ }^{46}$ Arrieta Martínez de Pisón, J. et alt., Guía docente de ... op. cit., p. 4. 


\section{Zulema Calderón Corredor}

ya conquistado de unidad y autonomía docente ${ }^{47}$ y científica, no significa que no sea ya necesario plantearse preguntas por sus principios, sus fines o sus límites. Hay quien afirma incluso que "no sólo la existencia sino la discusión acerca de la autonomía científica de esta disciplina, así como su carácter jurídico, si tiene sentido, es para dudar de ella. Entre otros motivos, porque la realidad actual del Derecho Financiero ha ganado exponencialmente en complejidad"48.

Se trata además de un área jurídica en la que el positivismo formalista que acompañó a su construcción científica ha dejado una herencia que está poniendo en crisis algunos pilares de la denominada "construcción clásica" ${ }^{49}$. Soler Roch ${ }^{50}$ lo expresa muy bien cuando afirma: "Dentro de un marco aparentemente ambicioso y omnicomprensivo como el de la concepción unitaria del Derecho Financiero, un objeto de conocimiento exclusivamente anclado en el Derecho positivo puede mermar la validez de aquella propuesta científica, en la medida en que nuestra disciplina no afronte el estudio de determinados problemas, bien porque estén mal resueltos en el Derecho positivo o bien porque no estén resueltos en absoluto".

El carácter unitario del fenómeno financiero no parece una cuestión bien resuelta desde el momento en que la vinculación ingreso-gasto no ha encontrado reflejo en la doctrina del Derecho financiero. Esta circunstancia se ha relacionado con la concepción autoritaria del impuesto y del poder financiero en la escuela alemana de Derecho Público primero y en la doctrina italiana después. Es decir, la obligatoriedad del pago deja de fundamentarse en una realidad concreta, en algo exterior al mismo, ya fuera la noción escolástica de bien común ya la idea de gasto público aprobado en el Presupuesto. Esta fue una influencia decisiva en la formación del sistema dogmático del Derecho Financiero contemporáneo y en la cual el fenómeno tributario pierde toda su conexión con los gastos públicos. "El impuesto aparece, así, desprovisto de toda fundamentación en un criterio ma-

\footnotetext{
${ }^{47}$ Fue F. Sáinz de Bujanda el que desde 1945 defendió la creación, en nuestras Facultades de Derecho, de una cátedra cuya misión específica consistiera en el estudio de los problemas jurídico-financieros. El Plan de Estudios de la Licenciatura de Derecho de 1953 reconoció la autonomía del Derecho Financiero y Tributario incluyéndolo como asignatura de $4^{\circ}$ Curso y lo distinguió de la de Hacienda Pública del curso anterior. Posteriormente, el Real Decreto 1424/1990, de 26 de octubre, por el que se establece el título universitario oficial de Licenciado en Derecho y las directrices generales propias de los planes de estudios conducentes a la obtención de aquél, configura el Derecho Financiero y Tributario como materia troncal de segundo ciclo, cuyo contenido abarca: "La financiación pública. Derecho Presupuestario. Derecho Tributario. Derecho de los gastos públicos”, que corresponde impartir, exclusivamente, al área de conocimiento de Derecho Financiero (Tercera directriz del Anexo).

48 Ruiz Almendral, V., "Bolonia como oportunidad para renovar la enseñanza (y la investigación) en Derecho Tributario en España”. García-Herrera, C. (coord.), VII Jornada metodológica ... op. cit., p. 121.

49 Se refiere en particular a la concepción unitaria del Derecho Financiero y Tributario, a la creación dogmática y a su autonomía frente a otras disciplinas. Cfr. Soler Roch, M ${ }^{\mathrm{a}} \mathrm{T}$., "Reflexiones sobre la evolución del concepto del Derecho Financiero”. I Jornada Metodológica ... op. cit., pp. 58 y ss.

50 Ibídem.
} 
terial de justicia....El tributo se concibe, en esta tendencia doctrinal, como una prestación pecuniaria abstracta, no causal, en la que toda referencia a fin (procurar al ente público los ingresos necesarios para el mantenimiento de los servicios públicos) parece jurídicamente irrelevante" ${ }^{51}$.

En el caso español la obligación de contribuir es un deber ordenado teleológicamente conforme al artículo 31.1 de la CE: "Todos contribuirán al sostenimiento de los gastos públicos". No obstante, no queda explicitado en el citado texto el propio fin al que se dirige este gasto público más allá de la consecución de una asignación equitativa de los recursos públicos (artículo 31.2 CE). La doctrina ${ }^{52}$ ha señalado que nuestro actual artículo 31.2 no ofrece criterios suficientes para un verdadero control en la justicia del gasto público. Aunque este se encuentra sometido a directrices jurídicas, el criterio de la "asignación equitativa" del gasto público puede, si acaso, remitir a otros objetivos constitucionalmente protegidos, pero difícilmente puede constituirse en un criterio unitario de justicia tributaria más allá de un control de asignación de mínimos existenciales.

La función interpretativa del elemento teleológico propuesto resulta de especial interés habida cuenta de la abundancia de conceptos jurídicos indeterminados relevantes en el área financiera y tributaria. La Constitución Española (principios del art. 31.1, entre otros) contiene conceptos de relevancia jurídica cuya definición y contenido no se encuentra en el resto del articulado ni tampoco en otras ramas del Derecho. Tampoco el Tribunal Constitucional ha aportado una argumentación clarificadora suficiente sobre el sentido y alcance del principio de igualdad tributaria y el de capacidad económica como medida de esa igualdad, por ejemplo ${ }^{53}$.

El elemento teleológico resulta por ello de especial importancia si queremos formar en el los alumnos la capacidad crítica, lo que conlleva "el desarrollo de destrezas para el razonamiento y juicio crítico.... Ello implica valorar los distintos enfoques que puede presentar una situación o un problema en la realidad social, detectando las posibles deficiencias y las propuestas y soluciones que ofrece la aplicación del Derecho y de las normas jurídicas ... pudiendo ofrecer propuestas para su superación y mejora" ${ }^{54}$.

51 Rodríguez Bereijo, A. B., Introducción al estudio del Derecho Financiero: un ensayo sobre los fundamentos teóricos del Derecho Financiero, IEF, Ministerio de Hacienda, 1976. p. 88. Esta misma concepción va unida a una calificación del principio de capacidad contributiva como mero criterio orientador, de directriz de la política legislativa.

52 Distintas referencias a la cuestión pueden verse en el siguiente trabajo: Herrera Molina, P. M., “¿Existe un principio general de justicia financiera?”, I Jornada Metodológica ... op. cit., pp. 271 y ss.

${ }^{53}$ La doctrina ha reprochado al Tribunal Constitucional la ausencia de esa labor de clarificación. Cfr. Rodríguez Bereijo, Alvaro B., Igualdad tributaria y tutela constitucional. Un estudio de jurisprudencia, Marcial Pons, Madrid. 2011. p. 16.

${ }^{54}$ Competencias y su evaluación. Extracto de la Memoria de Verificación del Título de Grado en Derecho. op. cit., p. 4. 


\section{ELEMENTO ANTROPOLÓGICO DE LA REALIDAD FINANCIERA Y TRIBUTARIA.}

Decíamos antes que la formación de nuestros juristas es un objetivo que dependerá de nuestra idea acerca de lo que es el Derecho. Al hacerse esta pregunta Hervada afirma que "no es extraño la diversidad en las nociones vigentes sobre lo que es el Derecho, pues la noción que del mismo se tiene depende de la noción previa del hombre y de la sociedad" 55 .

\section{a.- Como elemento normativo}

En efecto, en las distintas posturas que existen sobre lo que es el Derecho existe un componente antropológico que debe hacerse explícito y que, como punto de referencia de la realidad jurídica, debe actuar como elemento normativo de la misma.

Coincidimos con Hervada ${ }^{56}$ cuando explica esta realidad diciendo: “...el hombre es como es, no solo en el plano físico y biológico, sino también en el moral. El hombre no es, en el ámbito moral, capricho o pura libertad. El hombre es persona y ser persona comporta una dignidad, un modo específico de ser, que hace que haya cosas en su actuar...que sean buenas o malas en sí mismas, independientemente que le guste o no le guste al hombre, de que lo quiera o no lo quiera. ...Aquellas exigencias, respecto de sí mismo y respecto de los demás, que dimanan de la índole personal del hombre, es lo que constituye el orden moral y jurídico natural, que se expresa en la ley natural".

En nuestra opinión, esta legalidad natural o manera de ser del hombre tiene efectos directos en materia tributaria como por ejemplo en la proyección del derecho de propiedad sobre el principio de no confiscatoriedad del sistema tributario justo, o la manifestación de las necesidades personales y familiares en la medición de la capacidad contributiva (mínimo personal y familiar). El tratamiento fiscal de otras realidades sociales o económicas como la empresa, la herencia, la filantropía o las situaciones de enfermedad o dependencia, son un reflejo de que el Derecho incorpora un componente antropológico claro.

Si además queremos formar a nuestros alumnos en el compromiso ético y con ello en la "sensibilidad social para identificar los dilemas éticos que plantea la sociedad y la profesión jurídica" ${ }^{77}$ y en la "capacidad para utilizar los principios y valores constitucionales, el respeto a los derechos humanos, con especial atención a la igualdad

55 Hervada Xiberta, J., ¿Qué es el derecho?... op. cit., p. 23.

56 Ibídem, p. 146. Una de las veces que analiza la filosofía inherente al positivismo y su alejamiento de la realidad del hombre es cuando añade la frase que transcribimos.

57 Competencias y su evaluación. Extracto de la Memoria de Verificación del Título de Grado en Derecho. op. cit., p. 5. 
entre hombres y mujeres, la sostenibilidad y la cultura de la paz, como herramientas de trabajo en la interpretación del ordenamiento jurídico"58 , está justificado un espacio en nuestra reflexión docente para el elemento antropológico.

Esta reflexión no puede dejar al margen la evolución histórica que ha experimentado la concepción del hombre acerca de sí mismo. En el contexto antropológico donde se pensó inicialmente el arte jurídico como el discernimiento de lo justo, predominaba una visión armónica entre el carácter teleológico del hombre, su bien, su libertad y su naturaleza social ${ }^{59}$. Con la Modernidad, a partir del nominalismo primero y con el desarrollo de las ciencias naturales después, desaparece de la filosofía antropológica la idea de naturaleza humana y con ello el elemento teleológico y relacional del ser humano. Una concepción individualista del hombre se va haciendo presente en el pensamiento político y en la vida social, instaurando la contraposición entre el bien individual y el bien común. Esta forma de entender las relaciones entre los individuos y las de estos con la sociedad hace imposible no valorar como un "trade-off" los bienes afectados por el fenómeno tributario (principios de justicia y eficiencia, por ejemplo).

\section{b.- Como elemento material de proyección de la justicia distributiva}

Desde una concepción del Derecho como discernimiento de lo justo y un concepto de lo justo como lo debido a alguien o a la comunidad (el suum), la persona y sus circunstancias adquieren por fuerza relevancia jurídica. Esta relevancia está especialmente presente en el tipo de igualdad que define a la justicia en las relaciones entre el todo social y el individuo, la justicia distributiva. Así como en la justicia conmutativa, más propia de la relación entre particulares, la igualdad entre las prestaciones es aritmética y no se hace acepción de personas, en la justicia distributiva la igualdad entre las prestaciones es proporcional, estando esa proporcionalidad referida a una circunstancia que diferencia a unos individuos de otros en relación a su obligación de contribuir y con ello al bien común. El elemento antropológico o lo que nos diferencia a unos de otros, adquiere así centralidad en la comprensión del fenómeno financiero y tributario.

El principio de igualdad trasladado al ámbito tributario no puede por ello reconducirse a una mera interdicción de la arbitrariedad de los poderes públicos. El

${ }^{58}$ Guía docente de la Asignatura de Derecho Financiero y Tributario I. Universidad de Valencia. 2012. 2013. p. 2.

${ }^{59}$ Conforme a la corriente aristotélica tradicional en torno a las virtudes humanas el bien del hombre es el mismo que el bien de aquellos otros que constituyen junto a él la comunidad humana. Cfr. Macintyre, A., Tras la virtud. Traducción castellana de Amelia Valcarce, Crítica,. Barcelona, 2009, $4^{\text {a }}$ edición. pp. 281-281. Antonio Truyol y Serra afirma incluso: "El hombre no sólo es social, como lo son otros animales, sino que es también político, y sólo él es tal. La polis es la condición de la vida humana buena, de una vida humana dotada de aquella plenitud que a la esencia del hombre como animal racional corresponde". Historia de la Filosofía del Derecho y del Estado ... op. cit., p. 161. 
principio de igualdad en los tributos, conforme a la justicia distributiva, se proyecta distribuyendo la carga conforme a la distinta condición de los individuos respecto del fin, condición que consiste básicamente en valorar la capacidad económica. En esta valoración habrán de considerarse, dentro de las posibilidades que ofrece la técnica legislativa, todas las circunstancias que afecten de forma significativa a esa capacidad. Por ello, tanto la elección de la unidad contribuyente (individuofamilia), el sistema de ponderación de rentas familiares (splitting, quotient, o sistema de cociente familiar con deducción) como la relevancia fiscal de gastos relacionados con el bien común (fin del impuesto), son cuestiones que reflejan en mayor o menor medida el compromiso de un sistema tributario con la justicia distributiva.

\section{c.- Como fundamento y graduación del principio de subsidiariedad}

Con el replanteamiento de la pregunta por el fin del impuesto, surge la del papel que en este fin desempeña el individuo, la sociedad y el Estado. El elemento antropológico introduce además la relevancia normativa de la idea de naturaleza humana y su relación con la justicia distributiva en el fenómeno financiero y tributario. Pues bien, quedaría por formular la pregunta acerca de la libertad y el aspecto ético de la acción humana en relación al bien común y con ello la pregunta por el principio de subsidiariedad ${ }^{60}$. Este principio se sitúa dentro del problema que toda convivencia supone, el de armonizar el orden y las exigencias de la vida en común con el ejercicio de la libertad y el respeto a la dignidad de las personas. Se trata de un principio que, junto con la idea de bien común, constituye un auténtico marco o límite de la actividad financiera y tributaria.

La reflexión propuesta es especialmente oportuna en el caso español teniendo en cuenta el papel activo que la Constitución le asigna al Estado. En un trabajo acerca del mismo a la luz de la economía política de las constituciones G. Brennan concluye con los siguientes comentarios: “...la Constitución tiene una visión optimista y positiva del Gobierno (y de la democracia mayoritaria), al que no ve como un Leviatán potencial, y al que asigna la realización o la promoción de una gran variedad de funciones y actividades. El gran número de bienes públicos (sociales y preferentes) cuya provisión se le asigna al sector público, constituye una clara muestra de esta visión optimista del Estado" ${ }^{61}$. Una prueba de ello son los

${ }^{60}$ Históricamente han sido las circunstancias peculiares de los estados modernos las que han motivado que el término, ya implícito en las aportaciones de Aristóteles (en su Política I, 1, sobre el orden político de la ciudad) y de Santo Tomás (en su Summa contra los Gentiles, III, 71, 4, en relación al respeto del buen gobierno a la naturaleza de las cosas gobernadas) se haya hecho "explícito" y se haya profundizado en su sentido y alcance. Dos de las referencias explícitas más destacadas sobre la cuestión se encuentran en Doctrina Social de la Iglesia y pertenecen a LEÓN XXIII en la Rerum Novarum. Carta encíclica sobre la situación de los obreros, n 35, y a PÍO XI en la Quadragesimo Anno, nº 79.

${ }^{61}$ Brennan, G. y Casas Pardo, J., "La constitución española a la luz de la economía política de las constituciones”. Hacienda Pública Española, n 116, 1990. p. 67. 
compromisos de actuación que asume el Estado, entre otros, en los artículos que la Constitución dedica a los principios rectores de la política social y económica (arts. 39 a 52). En estos principios se inspiran muchas medidas legislativas, incluidas las de naturaleza tributaria, sin que exista una reflexión previa suficiente sobre el papel que en esas materias desempeña o debe desempeñar la sociedad civil. Con ello se corre el peligro de politizar la vida social y de restar oportunidades de expresión a la libertad y creatividad individuales y sociales.

En una valoración realizada de la presencia e incidencia del Estado en la vida social y económica española, una valoración del llamado "peso fiscal", se afirma: "A lo expuesto se han de agregar los efectos negativos que en la solidaridad y en la colaboración de los ciudadanos se dan en razón de la exacción de los impuestos.... Sin pretender que la enumeración sea agotadora, se citan los casos y los fenómenos que, indudablemente, generan desánimo social y deterioran los vínculos individuales de la sociedad civil"62. Más adelante se comenta que el hecho de que la sociedad se haya desentendido de muchas prestaciones es una de las causas que explica el incremento en el volumen de los gastos públicos ${ }^{63}$. Es interesante observar también cómo la influencia del Derecho Comunitario viene a formular también la pregunta por el principio de subsidiariedad a través de la fuerza expansiva de las libertades comunitarias, el principio de no discriminación, la prohibición de exacciones de efecto equivalente y ayudas de Estado o el principio "quien contamina, paga" 64.

La reflexión en el principio de subsidiariedad, desde una idea previa de lo que es el hombre y de cómo es su vida en comunidad, resulta de especial interés en el Derecho Financiero y Tributario. Responde a la necesidad de dar a conocer la realidad sobre la que se aplica el Derecho y de formar en nuestros juristas la capacidad de hacer una lectura normativa de esa realidad. "No es concebible un proceso de enseñanza-aprendizaje del Derecho que bajo la capa de mera técnica jurídica eluda el tratamiento de los valores inspiradores del ordenamiento, de las necesidades sociales que ha de resolver y de los criterios en que se basa para las soluciones que adopta" ${ }^{65}$.

${ }^{62}$ Este índice pretende valorar el nivel de entorpecimiento, rozamiento, o coste indirecto que se deriva de la actividad pública y su financiación, teniendo para ello en cuenta efectos y consecuencias no considerados por índices tradicionales. Albiñana, C.,"Estado y peso fiscal en España”, Cuenta y Razón, n 31, 1987. p. 31.

${ }^{63}$ Ibídem, pp. 31-33. En su opinión la mayor aceptación de los impuestos por parte de los españoles no autoriza a una ramificación injustificada de los fines y funciones del Estado en organizaciones e instituciones de ámbito general y territorial. Por otra parte califica de inusitado el volumen que está adquiriendo la demanda de protección por parte del Estado, el cual se está convirtiendo en asegurador de "infortunios y calamidades”. Las responsabilidades del mismo se están extendiendo además a límites que hasta hace poco tiempo eran insospechados.

${ }^{64}$ C. García Novoa se refiere con esta expresión a la recuperación de la visión sustancialista del Derecho Financiero y Tributario frente a la tendencia al estatalismo, aunque entendemos que son cuestiones que también están relacionados con el principio de subsidiariedad. Cfr. "Algunas reflexiones sobre cuestiones de concepto y método en Derecho Financiero y Tributario”, I Jornada Metodológica ... op. cit., p. 116.

65 "Metodología docente", Guía docente de la Asignatura de Derecho Financiero y Tributario I. Universidad de Valencia. 2012-2013. p. 6. 
Se trata de una reflexión que, creemos, no debe circunscribirse a los parámetros que aporta nuestro texto constitucional, pues la realidad social es una realidad más amplia, que además es dinámica y compleja. Cuando García Añoveros reflexiona sobre el papel fundamental que jugó la Constitución Española de 1978 en la consolidación del Estado de Derecho y con ello en la del Derecho Financiero y Tributario, concluye afirmando: "Pero no debe entenderse esta afirmación en el sentido de que el Derecho Financiero sólo existe plenamente allí donde hay una Constitución" ${ }^{66}$. En el fondo yace la pregunta acerca de si tiene sentido reflexionar sobre la justicia en el ámbito financiero y tributario, más allá del texto constitucional. Nosotros creemos que sí.

\section{ELEMENTO METODOLÓGICO EN LO JUSTO FINANCIERO Y TRIBUTARIO.}

En una propuesta metodológica reciente para la reconstrucción del Derecho Financiero y Tributario del S. XXI, se reconoce ${ }^{67}$ que la Constitución Española de 1978 alteró profundamente las bases científicas del Derecho Financiero, en un aspecto íntimamente relacionado con la cuestión metodológica. Hasta entonces la metodología giraba en torno a la fundamentación basada en los principios aplicables al ordenamiento financiero y tributario (método principialista desarrollado por Sainz de Bujanda). La recepción constitucional de estos principios, se dice, confirma y a la vez supera aquella fundamentación, desembarazando de idealismo al Derecho Financiero y Tributario y cimentándolo más sólidamente. Se abre así un periodo de gran confianza en los frutos de esta línea metodológica centrada en el Derecho Financiero Constitucional. Ese proceso de alumbramiento, tutelado por el Tribunal Constitucional, está acompañado por la integración en el ordenamiento interno de los principios del Derecho Comunitario y de los del Derecho Tributario Internacional.

Esta línea metodológica es ampliamente recogida en las guías docentes de las asignaturas del área financiera y tributaria ${ }^{68}$. Así, dentro de las competencias específicas se incluye la de "interpretar las normas jurídicas conforme a los criterios de uso habitual, en especial, el de la conformidad con las reglas, los principios y los valores constitucionales" ${ }^{\prime 9}$ o la "capacidad para utilizar los principios y valores constitucio-

${ }^{66}$ García Añoveros, J., "El discurso del Método en el ámbito Hacendístico", Conferencia pronunciada en Barcelona en marzo de 2000, I Jornada Metodológica "Jaime García Añoveros" sobre la metodología académica y la enseñanza del Derecho Financiero y Tributario, Documento n 11/02, Instituto de Estudios Fiscales, 2002.

${ }^{67}$ Escribano López, F.,"Algunas propuestas metodológicas para la (re)construcción de un Derecho Financiero del siglo XXI". I Jornada Metodológica ... op. cit., p. 32.

${ }^{68}$ Recogida por la ANECA como "Capacidad para utilizar los principios y valores constitucionales como herramienta de trabajo en la interpretación del ordenamiento jurídico" como competencia específica de la titulación de Derecho. Cfr. Libro Blanco del Título de Grado en Derecho. op. cit., .p. 181.

${ }^{69}$ Arrieta MArtínez de Pisón, J. et alt., Guía docente de la asignatura ... op. cit., p. 4. 
nales como herramienta de trabajo en la interpretación del ordenamiento jurídico"70. No obstante, junto a ellas, esas mismas guías docentes ${ }^{71}$ proponen también la adquisición de "una actitud de percepción critica de la realidad y de las ideas, y de apertura

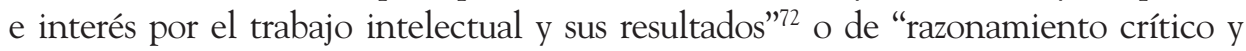
creativo", permitiendo al alumno "desarrollar sus propias valoraciones a partir de una reflexión sistemática sobre los fundamentos en los que se asientan las ideas, juicios y acciones, y las consecuencias de las acciones propias y ajenas"73. La pregunta que de forma natural se plantea es: ies esta línea metodológica adecuada a los objetivos que nos proponemos al enseñar Derecho Financiero y Tributario?.

Esta actitud metodológica se ha trasladado también a la producción doctrinal cuyo foco de atención describe Soler Roch ${ }^{74}$ cuando afirma: "la atención doctrinal a la Constitución española se ha convertido en el principal eje del análisis jurídico-financiero". En su opinión, el principal inconveniente del abandono en la creación dogmática es una excesiva dependencia del Derecho positivo lo cual le lleva a plantearse una serie de interrogantes en relación con la función científica del profesor universitario, que ha pasado del dogma al dictamen y de teórico a comentarista. Tampoco se muestra favorable al hecho de que sea el Tribunal Constitucional el que tome la antorcha dogmática ni a la recepción acrítica de su jurisprudencia ${ }^{75}$. Se sugiere incluso ${ }^{76}$ que es el debate metodológico la cuestión sobre la que versa hoy el debate central en el Derecho Tributario español.

Una vez apuntados, aunque sea brevemente, algunos de los retos metodológicos de la actividad docente y doctrinal, queda por proponer algún elemento de reflexión que facilite una respuesta. Además, el marco de renovación que supone el proceso iniciado en Bolonia es la mejor excusa para proponer esa reflexión metodológica. Sobre todo porque al poner el acento en el aprendizaje autónomo del alumno y en su implicación, ya no son suficientes las metodologías pasivas de enseñanza, tan poco adecuadas además a una idea del Derecho como praxis de discernimiento de lo justo.

Desde la concepción pluridimensional del Derecho Financiero y Tributario que ofrecen los elementos teleológico y antropológico ya expuestos, se deduce la existencia,

${ }^{70}$ Universidad de Cantabria. Guía docente de la asignatura de Derecho Financiero. Grado en Derecho. 2012-2013. P. 3.

${ }^{71}$ La ANECA también recoge como competencias específicas la "adquisición de una conciencia crítica en el análisis del ordenamiento jurídico y desarrollo de la dialéctica jurídica” y la "adquisición de valores y principios éticos”. Cfr. Libro Blanco del Título de Grado en Derecho. op. cit., p. 181.

${ }^{72}$ Arrieta Martínez de Pisón, J. et alt., Guía docente de la asignatura ... op. cit., Competencias generales. p. 4.

${ }^{73}$ Universidad de Cantabria. Guía docente de ... op. cit., p. 3.

${ }^{74}$ Soler Roch, M ${ }^{\mathrm{a}}$ T.,"Reflexiones sobre la evolución del concepto del Derecho Financiero". I Jornada Metodológica ... op. cit., p. 63.

${ }^{75}$ Ibídem.

${ }^{76}$ Palao Taboada, C., "El papel de los profesores de Derecho Financiero y Tributario en la elaboración de la Legislación Tributaria”. I Jornada Metodológica ... op. cit., p. 69. 


\section{Zulema Calderón Corredor}

en el plano del ser, de una realidad objetiva de impuesto justo anterior a la norma de Derecho positivo. Los elementos formales contenidos en este Derecho positivo son solo manifestación de un orden más complejo. El Derecho Financiero y Tributario tiene por objeto el aspecto jurídico de una realidad humana, social y económica cuyo componente normativo debe quedar reflejado en la legislación y en la forma de interpretarla.

García Añoveros, cuando se refiere a la posibilidad de conocimiento científico de la actividad financiera afirma: "su conocimiento cabal requiere el dominio de varias y diversas disciplinas, supongamos que científicas. La actividad financiera, para su comprensión íntegra, requiere una aplicación y un procedimiento multidisciplinar que es una cosa muy distinta de un método (científico) sincrético"77. Más adelante se refiere a distintos profesionales del Derecho, a los estudiosos, a los profesores y se pregunta: “¿Cómo van a conseguir lo mejor de su arte (me resisto a llamarle ciencia) si cierran los ojos a la realidad humana tal como es?"78. La función del jurista, en las distintas fases de la vida del derecho, es una función crítica, siendo imprescindible para realizar esta función la utilización de distintos enfoques que permitan arrojar luz sobre un fenómeno complejo. Se trataría entonces de valerse de un método, no un método sincrético sino jurídico, aunque no un método jurídico puro incontaminado de nada que no fuera derecho ${ }^{79}$.

La forma de materializar esta propuesta no es unívoca. Como tampoco lo son las capacidades de reflexión de los docentes o las necesidades que surgen en las distintas asignaturas. Dentro de un mismo programa de contenidos se pueden aplicar distintas metodologías que tomen mayor o menor distancia respecto al Derecho positivo, o que reflejen un mayor esfuerzo interdisciplinar. En todo caso deberán responder a las expectativas que ya se están recogiendo en las guías docentes y que aspiran a situar a los alumnos "en condiciones de que por ellos mismos descubran y vayan avanzando en la solución de los problemas planteados" para lo cual será indispensable "imbuirles del rigor en el razonamiento, de la claridad en la separación de aspectos diferentes, en que no caigan en saltos lógicos o en prejuicios sobre el contenido o la interpretación de las normas relevantes, y, en definitiva, en que resulten capacitados para alcanzar y ofrecer su propia solución a través de un adecuado razonamiento técnico-jurídico y de valores y principios" 80 . La metodología empleada deberá ser capaz de formar al alumno en la "capacidad para percibir el carácter unitario del ordenamiento jurídico y la necesaria visión interdisciplinaria de los problemas jurídicos" ${ }^{81}$.

${ }^{77}$ García Añoveros, J., "El discurso del Método en ...”. op. cit., p. 17.

${ }^{78}$ Ibídem, p. 21.

${ }^{79}$ Ibídem.

80 "Metodología docente". Guía docente de la Asignatura de Derecho Financiero y Tributario I. Universidad de Valencia. 2012-2013. p. 7.

${ }^{81}$ Colao Marín, P.A. y Pastor del Pino, Mª C., Guía docente de la asignatura de Derecho Financiero y Tributario. op. cit., p. 5. 


\section{BIBLIOGRAFÍA.}

AA. VV., I Jornada Metodológica "Jaime García Añoveros" sobre la metodología académica y la enseñanza del Derecho Financiero y Tributario, Documento. $\mathrm{n}^{\mathrm{o}}$ 11/02. Instituto de Estudios Fiscales, Madrid, 2002.

AA. VV., Competencias y su evaluación. Extracto de la Memoria de Verificación del Título de Grado en Derecho, Universidad Pontificia Comillas, Competencias específicas académicas, 2013.

AA. VV., Guía docente de la Asignatura de Derecho Financiero y Tributario I, Universidad de Valencia, 2012-2013.

ABAD DÍAZ M. et. ALT., Notas de introducción al Derecho Financiero, Tecnos, Madrid, 1992.

AGUILAR RUBIO, M. et. ALT., "El aprendizaje del Derecho Financiero y Tributario en el marco del EEES: experiencias desde la Universidad de Almería (I), en PIÑA GARRIDO, L. (Coord.), VI Jornada metodológica de Derecho Financiero y Tributario "Jaime García Añoveros", La calidad jurídica de la producción normativa en España, Doc 30/2009. Instituto de Estudios Fiscales. Madrid, 2009, pp. 95-106.

ALARCÓN GARCÍA, G., "El aprendizaje cooperativo como metodología para la enseñanza de la materia Sistema fiscal español", en PIÑA GARRIDO, L. (Coord.), VI Jornada metodológica de Derecho Financiero y Tributario "Jaime García Añoveros", La calidad jurídica de la producción normativa en España, Doc 30/2009. Instituto de Estudios Fiscales, Madrid, 2009, pp. 119-130.

ALBIÑANA, C., "Estado y peso fiscal en España", Cuenta y Razón, nº 31, 1987. "Los tributos con fines no financieros", Economía española, cultura y sociedad, Homenaje a Juan Velarde, Tomo II, Eudema, Madrid, 1992, pp. 75-114.

ALMUDÍ CID, J. M. y MARTÍNEZ LAGO, M. Á.,"Presente y futuro de la enseñanza del Derecho Financiero y Tributario en la Universidad Complutense de Madrid: estudios de grado, posgrado y viabilidad de una "clínica jurídico-tributaria”, Comunicación al IV Congreso Nacional de Innovación Docente en Ciencias Jurídicas, 2011.

ANECA, Libro Blanco del Título de Grado en Derecho, LORENZO MERINO, F. (Coord.), Vigo, junio de 2005.

ARISTÓTELES, Ética a Nicómaco, Alianza editorial, 2004.

ARRIETA MARTÍNEZ DE PISÓN, J.; DELGADO PACHECO, A.; GAN. DARILLAS MARTOS, S. et. ALT., Guía docente de la asignatura de Fundamentos de Derecho Financiero y Tributario ( $3^{\circ}$ Grado en Derecho), Universidad Autónoma de Madrid, Curso 2013-2014.

BERTRÁN GIRON, M. y PÉREZ LARA, J. M., "Presentación del proyecto de innovación docente: Enseñanza del Derecho mediante supuestos prác- 
ticos interdisciplinares e interdepartamentales", en PIÑA GARRIDO, L. (Coord.), VI Jornada metodológica de Derecho Financiero y Tributario "Jaime García Añoveros", La calidad jurídica de la producción normativa en España, Doc 30/2009, Instituto de Estudios Fiscales, Madrid, 2009, pp. 45-54.

BONET SÁNCHEZ, M P. y ALGUACIL MARÍ, Mª P.,"Combinación de estrategias y metodologías para un aprendizaje efectivo del Derecho Tributario", en PIÑA GARRIDO, L., (Coord.), VI Jornada metodológica de Derecho Financiero y Tributario "Jaime García Añoveros", La calidad jurídica de la producción normativa en España, Doc 30/2009, Instituto de Estudios Fiscales, Madrid, 2009, pp. 65-74.

BRENNAN, G. y CASAS PARDO, J., "La constitución española a la luz de la economía política de las constituciones", Hacienda Pública Española, n ${ }^{\circ}$ 116, 1990, pp. 53-68.

CAAMAÑO ANIDO, M.A. y CALDERÓN CARRERO, J. M.: "Globalización económica y poder tributario: ¿hacia un nuevo Derecho Tributario?", Revista española de Derecho Financiero, n ${ }^{\circ} 114,2002$, pp. 245-288.

CARRERA RAYA, FCO. J., Manual de Derecho Financiero, Vol. I. Derecho Financiero y Teoría de los ingresos públicos, Ed. Tecnos, Madrid, 1993.

CASANA MERINO, F., "Nuevas técnicas docentes en Derecho Financiero y Tributario", en PIÑA GARRIDO, L. (Coord.), VI Jornada metodológica de Derecho Financiero y Tributario "Jaime García Añoveros", La calidad jurídica de la producción normativa en España, Doc 30/2009. Instituto de Estudios Fiscales, Madrid, 2009, pp. 153-158.

COLAO MARÍN, P. A y PASTOR DEL PINO, Mª C, Guía docente de la asignatura de Derecho Financiero y Tributario $\left(4^{\circ}\right.$ Grado en $\left.A D E\right)$, Universidad Politécnica de Cartagena, Curso 2012-2013.

COLLADO YURITA, M.A. y LUCHENA MOZO, G.M., Derecho Tributario. Parte general, Atelie, $2^{\mathrm{a}}$ edición, Barcelona.

CORTÉS DOMÍNGUEZ, M., "El principio de capacidad contributiva en el marco de la técnica jurídica", Revista de Derecho Financiero y Hacienda Pública, nº 61, 1965, pp. 975-1053.

ESCRIBANO LÓPEZ, F., “Algunas propuestas metodológicas para la (re) construcción de un Derecho Financiero del siglo XXI", I Jornada Metodológica "Jaime García Añoveros" sobre la metodología académica y la enseñanza del Derecho Financiero y Tributario. Documento $n^{\circ} 11 / 02$, Instituto de Estudios Fiscales, 2002, pp. 31-52.

GARCÍA AÑOVEROS, J., "El discurso del Método en el ámbito Hacendístico", Conferencia pronunciada en Barcelona en marzo de 2000, I Jornada Metodológica "Jaime García Añoveros" sobre la metodología académica y la enseñanza del Derecho Financiero y Tributario. Documento ${ }^{\circ} 11 / 02$, Instituto de Estudios Fiscales, 2002, pp. 15-27. 
GARCÍA-HERRERA, C. (Coord.), VII Jornada metodológica de Derecho Financiero y Tributario "Jaime García Añoveros", Interpretación del Derecho Financiero y Tributario. La asignatura de derecho Financiero y Tributario en los nuevos planes de estudios, Doc 12/2011, Instituto de Estudios Fiscales, Madrid. 2011.

GARCÍA NOVOA, C., "Algunas reflexiones sobre cuestiones de concepto y método en Derecho Financiero y Tributario", I Jornada Metodológica "Jaime García Añoveros" sobre la metodología académica y la enseñanza del Derecho Financiero y Tributario, Documento n ${ }^{\circ} 11 / 02$, Instituto de Estudios Fiscales, 2002, pp.111-129.

GINÉ FREIXES, N., "Cómo mejorar la docencia universitaria: El punto de vista del estudiantado”, Revista Complutense de Educación, Vol. 20 Núm. 1, 2009, pp. 117-134.

GONZÁlEZ GONZÁlEZ, A. I y HERRERO DE LA ESCOSURA, P., "Aplicación de nuevas metodologías docentes en Derecho Financiero y Tributario" en PIÑA GARRIDO, L. (Coord.): VI Jornada metodológica de Derecho Financiero y Tributario "Jaime García Añoveros", La calidad jurídica de la producción normativa en España, Doc 30/2009, Instituto de Estudios Fiscales, Madrid, 2009. pp. 19-33.

HERRERA MOLINA, P. M., Capacidad económica y sistema fiscal. Análisis del ordenamiento español a la luz del Derecho alemán, Prólogo de K. Tipke, Marcial Pons, Madrid, 1998, pp. 270-277.

“Existe un principio general de justicia financiera?”, I Jornada Metodológica "Jaime García Añoveros" sobre la metodología académica y la enseñanza del Derecho Financiero y Tributario, Documento $n^{\circ} 11 / 02$, Instituto de Estudios Fiscales, 2002.

HERVADA XIBERTA, J., Lecciones propedéuticas de filosofía del derecho, $3^{\text {a }}$ Ed. edit., Eunsa. Pamplona, 2000.

¿Qué es el derecho? La moderna respuesta del realismo jurídico, Eunsa, Pamplona, 2008.

LOPAZ PÉREZ, A., "El aprendizaje del Derecho Financiero y Tributario en el escenario del Espacio Europeo de Educación Superior: Metodologías tradicionales versus metodologías activas”, en PIÑA GARRIDO, L. (Coord.), VI Jornada metodológica de Derecho Financiero y Tributario "Jaime García Añoveros", La calidad jurídica de la producción normativa en España, Doc 30/2009, Instituto de Estudios Fiscales, Madrid, 2009, pp. 213-225.

MACINTYRE, A., Tras la virtud, Traducción castellana de Amelia Valcarce, Crític,. Barcelona. 2009, $4^{\mathrm{a}}$ edición.

MALVÁREZ PASCUAL, L. A.,"Trabajo cooperativo a través de las plataformas de teleformación para la creación de materiales compartidos en el área de Derecho Financiero", en PIÑA GARRIDO, L. (Coord.), VI Jornada 
metodológica de Derecho Financiero y Tributario "Jaime García Añoveros", La calidad jurídica de la producción normativa en España, Doc 30/2009, Instituto de Estudios Fiscales, Madrid, 2009, pp. 119-130.

MARTÍN DELGADO, J.M., "Los principios de capacidad económica e igualdad en la Constitución Española de 1978”, Hacienda Pública Española, n 60, Madrid, 1979, pp. 61-93.

NEGRO, D., Lo que Europa debe al Cristianismo, Unión Editorial, Madrid, 2004.

PALAO TABOADA, C., "Apogeo y crisis del principio de capacidad contributiva", Estudios jurídicos en homenaje a Federico de Castro, Tecnos, Madrid, 1976, pp. 375-426.

"El papel de los profesores de Derecho Financiero y Tributario en la elaboración de la Legislación Tributaria", I Jornada Metodológica "Jaime García Añoveros" sobre la metodología académica y la enseñanza del Derecho Financiero y Tributario, Documento ${ }^{\circ} 11 / 02$, Instituto de Estudios Fiscales, 2002, pp. 66-69.

"Nueva visita el principio de capacidad contributiva", Revista Española de Derecho Financiero, no ${ }^{\circ}$ 24, Cívitas, 2005, pp. 767-783.

PEDREIRA MENENDEZ, J y PASCUAL GONZÁLEZ, M. M.. "Una propuesta de praxis metodológica en el Derecho Financiero y Tributario", en PIÑA GARRIDO, L. (Coord.), VI Jornada metodológica de Derecho Financiero y Tributario "Jaime García Añoveros", La calidad jurídica de la producción normativa en España, Doc 30/2009, Instituto de Estudios Fiscales, Madrid. 2009. pp. 227-236.

PÉREZ DE AYALA, J. L., "Las cargas públicas: principios para su distribución”, Hacienda Pública Española, nº 59, 1979.

"El fundamento deontológico del impuesto, de la Ley fiscal y de la obligación tributaria", I Jornada Metodológica "Jaime García Añoveros" sobre la metodología académica y la enseñanza del Derecho Financiero y Tributario. Documento $n^{\circ}$ 11/02, Instituto de Estudios Fiscales, 2002, pp. 285-310.

PIÑA GARRIDO, L. (Coord.), VI Jornada metodológica de Derecho Financiero y Tributario "Jaime García Añoveros", La calidad jurídica de la producción normativa en España, Doc 30/2009, Instituto de Estudios Fiscales, Madrid, 2009.

QUERALT, J. M.; LOZANO SERRANO, C.; TEJERIZO LÓPEZ, J. M. y CASADO OlLERO, G., Curso de Derecho Financiero y Tributario, Tecnos. $20^{\mathrm{a}}$ edición, Madrid, 2009.

RADBRUCH, G., Introducción a la filosofía del Derecho, 1948, Traducción española, edit. Fondo de cultura económica, $1^{\text {a }}$ Ed. 1951, México. D.F., 1993, $5^{a}$ reimpresión.

RAMOS PRIETO, J., Guía Docente de la asignatura de Derecho Financiero. Experiencia piloto de aplicación del sistema europeo de créditos (ECTS), Univer- 
sidades Andaluzas-Universidad Pablo Olavide, Sevilla, Estudios Conjuntos Derecho/ADE. Curso académico: 2011-2012.

RODRÍGUEZ BEREIJO, A. B.: Introducción al estudio del Derecho Financiero: un ensayo sobre los fundamentos teóricos del Derecho Financiero, IEF, Ministerio de Hacienda, 1976.

Igualdad tributaria y tutela constitucional. Un estudio de jurisprudencia, Marcial Pons, Madrid, 2011.

ROMERO GARCÍA, F., "Evaluación de competencias en la enseñanza universitaria en el marco del EEES”, en PIÑA GARRIDO, L. (Coord.), VI Jornada metodológica de Derecho Financiero y Tributario "Jaime García Añoveros", La calidad jurídica de la producción normativa en España, Doc 30/2009, Instituto de Estudios Fiscales, Madrid, 2009, pp. 87-94.

RUIZ ALMENDRAL, V., "Bolonia como oportunidad para renovar la enseñanza (y la investigación) en Derecho Tributario en España”, en GARCÍA-HERRERA, C. (Coord.), VII Jornada metodológica de Derecho Financiero y Tributario "Jaime García Añoveros". Interpretación del Derecho Financiero y Tributario, La asignatura de derecho Financiero y Tributario en los nuevos planes de estudios,. Doc 12/2011, Instituto de Estudios Fiscales. Madrid, 2011, pp. 119-145.

SIMONS, H., The Personal Income Taxation. University Chicago Press, reimpresión de 1948.

SOLER ROCH, M ${ }^{\mathrm{a}}$ T., "Reflexiones sobre la evolución del concepto del Derecho Financiero", I Jornada Metodológica "Jaime García Añoveros" sobre la metodología académica y la enseñanza del Derecho Financiero y Tributario,. Documento ${ }^{\circ}$ 11/02, Instituto de Estudios Fiscales, 2002, pp. 58-65.

TIPKE, K., Moral tributaria del Estado y de los contribuyentes, Marcial Pons, Madrid, 2002.

TRUYOL Y SERRA, A., Historia de la Filosofía del Derecho y del Estado, Vol. 1, De los orígenes a la baja edad media, Alianza,. Madrid, 1995,12 a edición.

VALLE, V., "Una nota sobre los principios impositivos en perspectiva histórica", Papeles de Economía Española, n 87, 2001, pp. 44-57.

VALLET DE GOYTISOLO, J. B., "Derecho y economía”, en IGLESIAS PRADA, J. L. (Coord.), Estudios jurídicos en homenaje al profesor Aurelio Menéndez, Vol IV, Cívitas, 1996, pp. 5541-5554.

VALVERDE, C., Génesis, estructura y crisis de la modernidad, BAC, Madrid, 1996.

VILLEY, M., Filosofía del Derecho, Scire Universitaria. Barcelona, 2003. Traducción de Evaristo Palomar Maldonado.

ZUBIRI, I.,"Justicia distributiva: enfoques nuevos a un problema antiguo", Hacienda Pública Española, n 91, 1984, pp. 279-301. 